\title{
"TeLl Us, IRMA, Tell Us:" \\ (RE)FASHIONING NEO-VICTORIAN \\ MEMORY IN JOAN LINDSAY'S \\ PICNIC AT HANGING ROCK (1967)
}

Brno Studies in English

Volume 47, No. 1, 2021

ISSN 0524-6881 | e-ISSN 1805-0867

https://doi.org/10.5817/BSE2021-1-14

\section{EDUARDO VALLS OYARZUN}

\begin{abstract}
Neo-Victorian literature has drawn a great deal of attention in the past forty years due to its tantalizing ways of negotiating the interplay between history, memory, trauma and nostalgia. Even though Joan Lindsay's Picnic at Hanging Rock (1967) partakes in many of the issues that characterize neo-Victorian aesthetics, it has hardly been examined under the critical light of neo-Victorianism. The argument of the article assumes that the (re)presentation, scrutiny and (re)enactment of Victorian culture in the novel defies or at least transcends received readings of Victorian culture and engages in an active, yet permanent search for memory as fiction, the re-enactment of the past as a revealing dimension of the present and, last, but not least, a permanent negotiation with / of nostalgia as a creative and transformative force. The analysis will help interpret Lindsay's novel as an archetypal neo-Victorian novel, arguably a foundational one.
\end{abstract}

\section{Key words}

Neo-Victorian Studies; Picnic at Hanging Rock; Joan Lindsay; Australian Fiction; memory and history

\section{Introduction}

Neo-Victorian fiction has blossomed in the last forty years due to its tantalizing negotiation of history, memory, trauma and nostalgia. Furthermore, the multifarious condition of the genre has brought about a new way to engage different critical modes - ranging from post-colonialism to Gothic studies, neo-Historicism, neo-Marxism and the like - whereupon the neo-Victorian project ${ }^{1}$ can explore the specific and particular relationships late-twentieth, early twenty-first century authors, readers and critics establish with the Victorian period. In a sort of meta-cultural twist, neo-Victorian criticism does not deal simply with Victorian settings, (re)enactments and / or representations of Victorian culture, but rather with how neo-Victorian aesthetics helps construe the ongoing relationship between past and present through Victoriana. The key to this matter lies herein, in the "ongoing" trait, since the neo-Victorian project actively focuses on a sort of "imagination," or representation, I should argue, "on the move," a "kind of 
conceptual nomad, not so much lost as permanently restless and unsettled" (Kaplan 2007: 3). Arguably, the critical element of the neo-Victorian project focuses on reading the desire underpinning a variety of texts that "offer themselves as memory" (Mitchell 2010: 32), "not simply communicat[ing] or transmit[ting], but actively shap[ing] it" (Mitchell 2010: 34). In other words, texts that self-reflectively - or even by way of "immersion," as Boehm-Schnitker and Gruss argue (2010: 5 ) - ponder the "neo" element in neo-Victorian aesthetics are usually privileged as prime objects of analysis, for a text to play out as neo-Victorian arguably must "be self-consciously engaged with the act of (re)interpretation, (re)discovery and (re)vision concerning the Victorians" (Heilmann and Llewellyn 2010: 4), thereby producing a tantalizing "combination of a non-normative historical insight and present-day self-reflectiveness” (Chalupský 2020: 109).

Joan Lindsay's Picnic at Hanging Rock (1967) - a cultural phenomenon in its own right in Australia ${ }^{2}$ - should qualify easily for inclusion in this particular category; so it is all the more surprising that it has consistently failed to do so. Not only has it never been inducted into the neo-Victorian canon, it has persistently been overlooked as a viable entry, and quite inconspicuously too. Admittedly, Lindsay's book, set in the late austral summer of 1900, ticks all the "neo-Victorian" boxes, fulfils every expectation regarding issues of historicity and memory, self-reflexivity, trauma and nostalgia, and throws in for good measure an extra bonus of post-colonial cultural clash with a whiff of social struggle. And yet, neo-Victorian criticism has overlooked the novel in an almost neglectful, certainly unwitting manner. ${ }^{3}$

Picnic at Hanging Rock famously tells the story of a group of students from an all-girl college who set out on a field-trip to celebrate St. Valentine's Day in the year 1900 at Hanging Rock, on the outskirts of Mount Macedon, Victoria, fifty miles northwest of Melbourne. Out in the bush, three schoolgirls - Miranda, Marion Quade and Irma Leopold - and a maths teacher, Miss McCraw, go missing under mysterious circumstances, to wit, all the picnickers' watches stop at twelve o'clock, a reddish cloud materializes in the sky, sounds of drums are heard far off, among other curious happenings. A week later, one of the missing girls, Irma Leopold, is found by Michael Fitzhubert, the nephew of a local peer, and Albert Crundall, coachman of the said peer, but the girl has no memory whatsoever of the time she went missing. The text then zeroes in on the lives of several characters, mostly Europeans, whose circumstances are forever and inevitably changed by the influence of the Hanging Rock incident. The tragic deaths of another schoolgirl, Sara Waybourne, an orphan; a junior mistress in Appleyard college, Dora Lumley; and Mrs. Appleyard herself, the college headmistress consummate the consequences of the incident, even as the mystery is dismally left unsolved.

The conflation of cultural identities, i.e., "the clash between [a] supposedly "old" Europe embodied in the relatively "young" Australian national entity" (Bladen 2012: 178) informs most of the critical body the novel has spawned in the past fifty-two years. Classic assessments of the text range from the negotiation, (re)mapping and / or (re)invention of both geographical and cultural landscapes (Steele 2010; Bladen 2012; Holmqvist 2013; Mayr 2017), the inadequacy of a European conception of time in the "apparent timelessness of [the Australian]" 
outback (Steele 2010: 45; Rousseau 1987, Holmqvist 2013), the conspicuous absence of Aboriginal culture (McCarthy 2018) or the politics of the white-vanishing trope in the Australian tradition (Tilley 2012). Readings that are not particularly concerned with the dialectics of identity in a postcolonial context, conversely, focus chiefly on broader cultural issues, such as conflicts between man and nature (Kirkby 1978), sexual repression (McFarlane 1983: 42; Crick 1985: 234), or simply, as Kathleen Steele puts it, a variety of "feminist or classical readings" (2010: 34). Indeed, both critical schools, postcolonial and "classical" alike, have pointed out issues that bear great interest to neo-Victorian studies - cultural negotiations, postcolonial guilt and sexual repression, to quote a few - but overall no critical analysis has yet unfolded the possibilities Picnic at Hanging Rock has to offer in the context of neo-Victorian studies.

Not that the Victorian element in the novel has ever been foregrounded by scholars or critics. For it has, and abundantly too. More often than not, however, it has been interpreted as an ancillary part of a larger dialectical context whereby the construction of the "other" hinges on received receptions of Victorianism. Consider Pablo Armellino's remark that Picnic at Hanging Rock "perfectly embodies the anxieties of the Victorian age" and "presents an alternative perception of the outback" (2009: 77). Armellino's claim, posited in relation to the ideological construction of the colonial space, braces the argument that the text offers an "archetypical representation of the conflict between nature and civilization," wherein the rock is constructed as the "completely "other," an inapprehensible space "diametrically opposite to the orderliness of Mrs. Appleyard's College" (2009: 78). In other words, Armellino's remark requires Victorian culture to be construed as an oppressive, over-orderly social project that aims to challenge the modern subject, whose anxieties, in turn, drive him / her to rebel against the said project (Valls Oyarzun 2017: 14). Likewise, Marek Haltof believes the novel "is [...] about the end of the 'old world' and the disintegration of Victorian society" (1996: 811) embodied in Appleyard College, "an incongruent remnant of the Empire" (1996: 811); and Malcolm Crick discusses notions of "otherness" in the novel from a wide array of perspectives, all of which however brand the Victorian as a "barren cultural landscape, which denies basic impulses in human nature" and "stifles vitality and affection through a repressive regime of definitions and order" (1985: 233). By and large, the novel "has been co-opted into cultural discourse" ${ }^{4}$ on the grounds of certain "narrative contrasts" (Wild 2014: 124, 123), which divine in the Victorian element a code for moralism, oppression, sexual repression, order and decay, much like the "archetypal text of modernist anti-Victorianism"5 (Matthews 2010: 277). Critical discourses surrounding the novel subordinate this interpretation of Victorianism to expose different incarnations of the "other," in terms of culture, gender or identity, but consistently fail to query the actual representation of Victorianism, let alone the drive that prompts such representation.

This is the case in point. My argument assumes that the (re)presentation, scrutiny and (re)enactment of Victorian culture in the novel defies or at least transcends received readings of Victorian culture and engages in an active, yet permanent search for memory as fiction, the re-enactment of the past as a revealing 
dimension of the present and, last, but not least, a permanent negotiation with / of nostalgia as a creative and transformative force. The combination of all three helps construe Picnic at Hanging Rock not only as an archetypal neo-Victorian text, but also as a foundational one, for the relation between the text and the neo-Victorian critical project is twofold. Surely, as these pages will show, it is not just that the neo-Victorian project reveals many of the potential meanings of the novel; but rather that the novel, too, has a great deal to say about the neo-Victorian project as such.

\section{Cracking the neo-Victorian code}

At the core of Picnic at Hanging Rock lies a fundamental contradiction. The novel makes a painstaking effort to pass as a "chronicle of events" (Lindsay 2009: 9,128 ), that is, a seemingly objective account of facts, carefully set in temporal continuity and subject to causality. Dates are provided as markers ${ }^{6}$ of a timeline whereupon the characters' desires, frustrations, anxieties, gains and losses unfold. The linearity of the chronicle, as well as its purported objectivity point to history as prime cognitive model. However, at a certain point in the chronicle, the text becomes aware of the flaws pertaining to this particular narrative method, aptly observing that history is responsible for both revealing and obfuscating the self at once,

Although we are necessarily concerned, in a chronicle of events, with physical action by the light of day, history suggests that the human spirit wanders farthest in the silent hours between midnight and dawn. Those dark fruitful hours, seldom recorded, whose secret flowerings breed peace and war, loves and hates, the crowning or uncrowning of heads. What, for instance, is the plump little Empress of India planning in bed in a flannel nightgown at Balmoral, on this night in March in the year nineteen hundred, that makes her smile and purse her small obstinate mouth? Who knows? (Lindsay 2009: 128).

If "a chronicle of events" cannot account for the nightly wanders of the "human spirit," then the historical frame of narrative cannot penetrate the self in full. History itself, in a self-reflective slant, suggests its limitations, but does not state them overtly, which in turn intimates that the issue here at hand lies in the way a "chronicle of events" negotiates the self. Indeed, history can hardly give an account of the "dark fruitful hours [...] whose secret flowerings breed peace and war, loves and hates," or "the crowning or uncrowning heads" (Lindsay 2009: 128) executed in private. There are indeed secret processes outside the "human spirit" history cannot account for, and because these are divined as a series of events subject to time beyond history, it is fair to say they constitute a different manifestation of the self, operating on a separate time frame. Furthermore, the oblique comment on history aptly introduces a critique on Victorianism informed by a deconstruction of its ultimate symbol. The text renders Queen Victoria as a synecdoche for 
a grand narrative - Victorian Imperialism - but also as a "plump," "little," somewhat ridiculous individual, even as she lives through the experience of her most private and most secret self. The grandeur of the "Empress of India" depends on her invulnerability as a symbol, which signals to the inviolable, transcendent and communal nature of the Imperial ethos. Yet, however unassailing the symbol may seem, the "plump little" character in a "flannel nightgown," living through dream-time, opens up a myriad of possibilities, affectuously encoded as secret and private, which in turn, by definition, run contrary to the communal and public nature of the Imperial ethos. The subject of the Queen comprises two different timelines, as well as two different, almost opposite selves.

The fracture of subjectivity as shown by the interaction of different, even contradictory selves, as well as the intimation of a time frame that challenges the historical chronicle the novel sets out to convey make up for the contradiction sitting at the core of the novel. Indeed, as it will presently become apparent, Picnic at Hanging Rock progresses through self-contradiction, ${ }^{7}$ simultaneously affirming and discrediting both the internal logic of the chronicle and most common received notions regarding the Victorian self. In this fashion, the conflict reveals an internal drive that proves itself fully compatible with the neo-Victorian project.

Admittedly, the "most inclusive definition" of Victoriana in the context of the postmodern, as Cora Kaplan contends, should encompass "the self-conscious rewriting of historical narratives," not only "to highlight the suppressed histories of gender and sexuality, race, [...] empire," and the like, but also to defy "conventional understandings of the historical itself" (2007: 3-4). More often than not, Victoriana at its most comprehensive gravitates towards "a neo-Victorian story of difference" (Heilmann and Llewellyn 2010: 15), ${ }^{8}$ one that sets out to debunk the fetish of a fixed Victorian identity and to decentre Victorianism as its normative cultural correlative, whilst paradoxically asserting its privileged role in the configuration of the present. In that sense, the neo-Victorian project manages to live up to "Frederic Jameson's own challenge, to art and critical thought, to "think the present historically" (Mitchell 2010: 5; Jameson, 2003: ix), but only to some extent, for it reaches further than that. The neo-Victorian project rebrands Victorian past(s) as something akin to what Gilles Deleuze dubs as "artificial signs," that is, a code "which refer[s] to the past or the future as distinct dimensions of the present, dimensions on which the present might in turn depend" (2013: 98-99). "A scar," Deleuze illustrates, "is the sign not of a past wound but of "the present fact of being wounded"” (2013: 98). Victoriana in the late-twentieth and early-twenty first centuries arguably works thus. The Victorian past is unequivocally linked to the way in which we constitute the present, inasmuch as it is a sign of the present. ${ }^{9}$ This does not necessarily preclude causality or dialectics - much to Jameson's inclinations - in the form of history, quite the opposite, in fact; but since the present exceeds the limits of history as $a$ single sign of the past, it must also acknowledge a variety of different stories, memories, desires, gains and losses, pains and frustrations, which help negotiate the present at least as productively as history in dialectical terms does. It is the negotiation among those signs, in order to constitute the present, which lies at the core of the neo-Victorian as a story of difference. And, as it probably becomes apparent already, it also 
informs the contradictory dynamic sitting at the core of Picnic, which echoes Christian Gutleben's take on the project, as he reads "neo-Victorianism in terms of an inherently contradictory, backward-looking / longing engagement with nineteenth-century literary antecedents and techniques that precipitates rather than obstructs postmodern experimentation" (Kohlke 2010: 23).

\section{Fractured self out of sync}

A common reading of Victorianism in Picnic at Hanging Rock elaborates on the "imaginative possession and symbolic appropriation" (Tilley 2009: 39) of the Australian landscape Victorian colonialism displays. The site of otherness, "the Rock," as it were, "comes into conflict with" Victorian "society's need for control, order and definition" (Crick 1985: 234). The white settler, in turn, finds this conflict unfathomable, thereby relapsing into "an ordered world of ticking clocks, punctual meals and annual rituals" (Steele 2010: 44).

Time - or rather timelessness - here is of the essence, for "contemplating nature in the Australian landscape inevitably involves contemplating the vastness of time" (Bladen 2012: 173). Indeed, "temporal and spatial discourses" in "white-vanishing" narratives such as Picnic at Hanging Rock "are intertwined" (Tilley 2012: 203), up to a point in which both dimensions help unfold each other. In Picnic, "imaginative possession" of space would inevitably bring about the "symbolic appropriation" of time, prompting "nature and natural terrain," as Victoria Bladen suggests, to "constitute a window onto time" (2012: 173). Most interpretations of vastness of time or timelessness in the novel - like Bladen's - often aim to underpin a somewhat normative reading, to wit, the dialectical opposition between, on the one hand, a sublime Australian landscape - a space beyond comprehension and understanding - that overwhelms, on the other, the ravenous, yet invariably thwarted Victorian desire to control and assimilate the said landscape (Kirkby 1978: 255). ${ }^{10}$

Depictions of sublimity through time / timelessness perform a somewhat fixed and strong self, a stable Victorian construction, an agency fuelled by an "ordered "civilization" that fears its own death through assimilation by the space of otherness, the bush, "and cannot overcome the gothic landscapes of settler imaginations," to wit, "landscapes where time and people disappear" (Steele 2010: 44). It is the settler indeed who creates the dialectical discourse against which the Victorian identity can be defined, so much so that the negotiation of the landscape and the sublime experience it prompts consistently reinforces rather than challenges the formerly-assumed identity. Victorian characters therefore "do not try to understand what they" see, but "rather, [...] retreat into an ordered world of ticking clocks, punctual meals and annual rituals" (Steele 2010: 44), that is, the "suffocating routine" the vanishing schoolgirls arguably flee from (Lindsay 2009: 5).

Time is refracted through the prism of subjective historical perception: the apparent timelessness of Australia is tested against received notions of Victorian time, and the permanence of the colony juxtaposed to natural 
and historical time. [...] Victorians have effected permanent changes to the landscape; the transience they experience does not arise from their interaction with the physical environment, but from the comparative shortness of their history in relation to Australia's, ably demonstrated when the girls first see the Rock (Steele 2010: 45).

At any rate, as Kathleen Steele points out, the "apparent timelessness" of Australia is as much a consequence of Victorian consciousness as the "prism of subjective historical perception" effectively is (2010: 45). And it is the fleeting - and misleading - quality of "transience" Victorian minds endure, rather than the actual confrontation with Australia, that truly upsets the Victorian mind (Steele 2010: 45). And even though the landscape is aptly constructed as overpowering and permanent, the Victorian self, paradoxically, keeps reading it - albeit obliquely - as proof of its own immanence. By virtue of the Victorian voices - "which are" indeed "the only audible voices" (Steele 2010: 44) in the novel - the Victorian self both submits to and overcomes the Australian sublime, underscoring the former's everlasting presence in different levels of representation. As Elspeth Tilley points out, not even the most traumatic event in the novel - "the vanishing episode" - can be adequately credited to the almighty Australian landscape, insofar as "the tools employed by the vanished characters to escape the repressive order of their own time are explicitly those of order within Victorian culture: geometry, algebra and a Cartesian model of space" (2012: 168-169).

By and large, readings of the novel that focus on sublimity or enshrine the landscape and its apparent timelessness as an "other" only manage to work because they operate within the limits of the Victorian self, even if they make a virtue of not doing so. Dialectical interpretations of the novel that set out to affirm the presence of an autochthonous, independent Australian self, even as subtext, usually collapse under their own Victorian entrapments of sublimity and timelessness. Alternatively, by reassessing the idea of time as rendered by the Victorian perspective, the novel readily discloses a broken subject within the limits of a similarly fragmented structure of time the text subtly capitalizes on. This in turn helps understand that Picnic rewrites received notions of Victorianism, even if they represent them as working-sites the text operates on, in order to bring home precisely the "story of difference" (Heilmann and Llewellyn 2010: 15) that more often than not neo-Victorian fiction promotes.

Gilles Deleuze's philosophy on difference and repetition provides a suitable model to read both the structure of time and how it helps constitute subjectivity in the text. ${ }^{11}$ For Deleuze, time is a synthesis, ${ }^{12}$ that is, a contraction of "differences" that operates at three different levels (first to third synthesis). These in turn mark the "foundation of time," the "ground of time" and the fracture of time (Deleuze 2013: 91, 101, 111). ${ }^{13}$ The foundation of time is the synthesis of habit, "constituted ... in the repetition of instants. This synthesis" is caused by the self, through imagination. It "contracts the successive independent" - i.e., different "instants into one another" (Deleuze 2013: 91), prompting a connection among them that, in turn, accounts for the repetition of the said instants. The repetition thereby constitutes "the lived, or living present" (Deleuze 2013: 91), whilst past 
and future coalesce in it. These are not separate moments in time, but dimensions of the present. ${ }^{14}$ The present preserves the past in the form of habit, which points to the future in turn with a gesture that asserts all possible expectations contained within and by virtue of the present. This nonetheless "creates only a static" horizontal "line of time, which cannot account for the passage of the present" (Widder 2006: 409). The present is bound to pass, for "passing" is in the nature of the present. Therefore, Deleuze concludes there needs be a second synthesis of time, a second time in which the present can become past. This is the synthesis of memory. Deleuze then creates an intersection of timelines. The memory synthesizes the past in the second timeline. If the synthesis of habit signals to the foundation of empirical reality, the second synthesis refers in turn to the possibility of representation. The fundamental principles of psychological memory operate herein, since "every moment is at the same time perception and recollection, actual and virtual" (De Bolle 2010: 139). This means that present and pure past "differ in nature, but coexist as two different worlds" or a "world with two focuses," that of the actual and that of the virtual, "both coexisting in reality" (De Bolle 2010: 139, 142). As such, there is nothing more present than memory, which cannot be experienced in the past, even though it brings the focus of the past to the present. Since memory prompts the past to be relived in the present, the second synthesis of time refashions the present as a dimension of the past, for the present now becomes "the product of the synthesis of innumerable layers of virtual pasts" (Widder 2006: 409).

Identity becomes apparent here. The first synthesis of time is constituted by the "self," via imagination. The "self" arises in the first synthesis of time since "habit" lays "the foundation from which all other psychic phenomena derive" (Deleuze 2013: 99). The second synthesis, conversely, contracts all pasts in the memory, thus actualizing the past selves into present. These spawn the illusion of identity. Memory somehow works akin to a meta-narrative. It implies the negotiation of a subject and an object, or rather, an "I" and an "Other" (Deleuze 2013: 108). The narrative thus dwells on a representation of its own likeness, its own self, which, paradoxically constitutes the "other" that the narrative treats as its own "I." That treatment is truly a mask of sameness, for the "other" is the contraction of all the different selves through all the different times it comprises. The "I" is, therefore, an illusion, a mask of identity, that conceals "no essence, no identity [...] only difference" (Widder 2006: 408). Furthermore, this illusion truly makes the subject elusive. Because identity arises from a narrative, that very narrative collapses the moment it narrates itself, for it must always create an "other" to constitute the "I," a new mask to substitute, in turn, the old one. "It is," Deleuze argues, "as though the "I" were fractured from one end to the other" (Deleuze 2013: 108). This particular elusiveness, and the fracture it evinces, corresponds to a third synthesis of time, which refers to the ongoing process of bringing a new mask of identity each time around. Every mask conceals the underlying differences behind it, and since every new mask is different - we only construe its sameness because it is an illusion of sameness - every time we acknowledge the new self, we bring about the eternal return - after Nietzsche - of difference. 
The third synthesis of time lies in the elusiveness of the fracture. It is a "caesura" that recurs over and over again (Deleuze 2013: 111-112) and puts time out of joint even as it constitutes its structure. The fracture of the self is represented by a symbol, a signifier to which the totality of time is "adequate" (Deleuze 2013: 112), a trauma which harbours the coexistence of a multiplicity of subjects. The symbol appears as representation, that is, narrative. It may or may not happen. Its main function remains to separate two orders and to join them at once. Nathan Widder summarizes its effects, thus,

I am a multiplicity of subjects living different temporalities within the same not-so-unified being. These diverging subjects and times are brought together by way of their repetition and resonance with one another - the adults we knew or expected to be as child subjects, for example, resonate with the adult subjects we are among other adults and children - and the communication of the series is established by the crack that can never be fully defined for any of these subjectivities, but which serve as their enigmatic link. Certainly similarities can arise from this resonance, allowing the many series to be collapsed into one line of successive events that a single subject is taken to experience and remember. [...] One may come to think that one's later loves repeat a repressed original love for one's mother, forgetting that the different loves do not even refer to the same subject or that the love of one's mother may be only part of an adult subjectivity being projected onto childhood (2006: 411).

Widder fittingly brings out the structure of the Oedipus to illustrate his point, for Deleuze ultimately contends that trauma informs the third synthesis of time. Trauma characterizes the enigmatic and mysterious difference that returns with every mask of identity. We affirm our identity as sameness, we repeat the disguise of the "I" as many times as memory allows. Yet each time around, Deleuze argues, it is a new "I" invariably displaced from the series by trauma. The series, therefore, is established altogether by the eternal return of trauma. ${ }^{15}$ In this fashion, trauma works as the fundamental device that casts time and the self "out of joint" (Deleuze 2013: 112) even as it provides time and the self with a structure. All in all, the "scattered members" or fragments of the subject revolve around a secret, "the sublime image" of an enigma (Deleuze 2013: 112).

This last point alone should shed enough light to understand how Picnic at Hanging Rock fits Deleuze's model. The novel hinges on trauma in the form of an enigma, the disappearance of the three schoolgirls and the maths teacher, the "College mystery" (Lindsay 2009: 55, 60, 100, 112, 161, 168), as it were. Trauma punctuates the narrative, indeed, just as habit and memory set up its founding ground. Deleuze's syntheses of time work along the basis of repetition. Whether empirical (habit), virtual (memory) or enigmatic (trauma), repetition, recurrence and iteration constitute the temporal correlative of difference (repetition being the synthesis of difference-in-itself). ${ }^{16}$ The unfathomable quality of the Rock, its resilience as a symbol of impenetrable chaos, for instance, arises largely as a consequence of the "elemental rhythms" characters in close contact with nature are 
aware of (Lindsay 2009: 153), but by which the Victorian subject generally feels overwhelmed. "The long violet shadows" encroach on the space "out at the Hanging Rock" to enact "their million-year-old pattern of summer-evenings across its secret face" (Lindsay 2009: 34, 68). Likewise, Edith, Irma, Marion and Miranda, the party ascending the Rock "[follow] the winding course of the creek upstream" (Lindsay 2009: 23), thus linking "the endless loops and turns of the wayward" brook (Lindsay 2009: 29). And as bellwether, Miranda eagerly progresses "cleaving wave after wave of dusty green" (Lindsay 2009: 33) on her resolute way to the top of the Rock. At the physical level of nature, recurrence and iteration appear as a "monumental configuration" to which "the human eye is woefully inadequate" (Lindsay 2013: 29), even though it is articulated, or rather is constituted, echoing Deleuze's first synthesis, into a pattern by means of that "very human eye." 17

The party move up to the Rock constituting a pattern of recurring spiral forms. Marion, Irma and Miranda (and Edith, who backs off at the last minute) start their journey confined within their own selves, "[walking] silently towards the lower slopes [...] each locked in the private world of her own perceptions" (Lindsay 2009: 30). As they climb up to the higher levels, they become more and more aware of their surroundings, and less involved in their own received Victorian subjectivity. When they reach the top, they not so much transcend to a timeless region or a "transpersonal subjectivity" (Hulbert 2016: 48) as they cease to synthesize time. Next to the monolith at the top of the Rock, "everything, if only you could see it clearly enough, is beautiful and complete," (Lindsay 2009: 35). The schoolgirls probably can see it thus, but surely the reader cannot, for the passage represents an instant that is no longer synthesized in a series. Hanging like the eponymous Rock, time is brought to a halt, and will remain so unless a synthesis of habit connects that very instant with another, thus constituting a present. Since time ceases to exist, so do the girls, promptly sliding away from the eyes of Edith, who retreats horrified to the cosy world of Victorian certainties. The ascent and the ensuing disappearance, Malcolm Crick points out, enacts the de-structuring of cultural identity (1985: 238), signalled, Deleuze would add, by the death of the ego (2013: 138). The ego always dies as a mask of sameness, a collapse of difference into illusive identity, yet in this particular case, the process of de-structuring goes all the way down, and death comes to pass as a result of bringing the "self" down to the very foundation of time, when the pattern ceases to exist.

The idea of the "pattern" is central to the internal logic of the text. It slices across different levels of narrative, from the physical map-out of the landscape in time, through the way in which memory operates - as it will presently become apparent - all the way up to the metafictional structure of the novel. The pattern of "geological formations," lichens on a stone, "stirring [...] shades," "lengthening shadows" or "summer evenings" (Lindsay 2009: 29, 32, 57, 65, 68) transform organically into a "pattern" of memory and narrative, as if the "elemental rhythms" of nature thus transcend the synthesis of habit and come to inform too the ensuing structural dimensions of time which the narrative comprises. Furthermore, the "pattern" arranges the text in a way that, at best, problematizes the nature of the story as chronicle, disproving the strength of the historical mode of narrative 
to a large extent. At any rate, the very presence of the "pattern" upends most common received Victorian notions of time and its relation to the self, revisiting subjectivity in a way which is fully consistent with the neo-Victorian project.

\section{Refashioning neo-Victorian memory}

The self-contradictory nature of Picnic at Hanging Rock stems from the "strains and tensions" (Lindsay 2009: 29) that arise when conflating the linear structure of the chronicle and the all-pervasive idea of the "pattern." At the core of this lies the trauma of the vanishing episode. Even though Picnic never eschews historical linearity completely, the "pattern" renders the chronicle problematic. Characters appear then in a multifarious construct resembling a fabric made up of "threads" or "segments" (Lindsay 2009: 152, 161) which in turn convey a manifold of different subjectivities. Lindsay then resorts to a number of literary techniques which stress synchrony, notably through dreams and memory, which give account of the different "private selves" the character comprises. These exist despite the chronicle - the surface effect or "optical illusion" of temporal continuity and identity (Widder 2006: 405) - yet become apparent because of it.

Dreams are very adept at enforcing subjectivity through the negotiation of selves, changing the "suet-grey mask" (Lindsay 2009: 128) of identity with every different recurring self. "Sara's little face," for instance, "is illumined [...] by a dream of Miranda so filled with love and joy that she carries it about with all next day" (Lindsay 2009: 128). The present tense suggests the synchrony of the self that is enforced by the dream and Sara's own identity. This changes with every new iteration of the self that resonates in the character. Likewise, "Mike is awake after a restless night, productive mainly of dreams of banking and packing," but "once he dreams" - present tense - "of Irma hurrying towards him down the corridor of a swaying train" (Lindsay 2009: 128) only for him to reject her advances and become master of his own desires. Irma, on the other hand, asserts her love for Mike after reliving the "picnic afternoon" in a sort of epiphanic dream (Lindsay 2009: 128).

Dreams convey the negotiation of subjectivity in synchrony with a given mask of identity. Memory, on the other hand, proves even more productive to a certain extent, for it manages to overcome a single synchrony and project the negotiation onto larger periods of time. The "I" appears to carry its own time along with itself, its own "fragments of identity" (Lindsay 2009: 120) which constitute the self that is synthesized by memory. The only conversation between Albert Crundall and Irma (in which the latter shows her gratitude to the former for having rescued her on the Rock) finishes at "exactly at three o'clock." It was a "brief conversation" but it "would inevitably be expanded, in memory, during [Albert's] fairly long life, to fill the entire content of a summer afternoon" (Lindsay 2009: 119). The three selves that inform Albert's identity (the character at three o'clock, the character in brief conversation with Irma, and the character in an undefined, long future) arise thanks to the synthesis of memory, and resonate in the same "present" narrative level. And yet, they are discontinuous, fragmented, so 
to speak, insofar as they constitute different timelines (a moment in time, the "entire content of a summer afternoon" and Albert's "fairly long life") and necessarily prompt "a multiplicity of subjects living different temporalities within the same not-so-unified being” (Widder 2006: 411). Irma, similarly, would remember Mike "most clearly" "watching a swan rising gracefully out of the reeds ahead" and "flapping away over the water until it disappeared amongst the willows." The self that is produced in that particular timeframe then crops up, time and again, all of a sudden, in such places as "the Bois de Boulogne" or "under the trees in Hyde Park" (Lindsay 2009: 121). Sara Waybourne, who "sometimes" feels "as if" she "was hundreds of years old," still has character-defining nightmares about her life in the orphanage, most particularly when she declares she wanted to become a "lady circus rider on a lovely white horse in a spangled dress" and got her head shaved in punishment instead (Lindsay 2009: 149-150). Mlle. De Poitiers, who in fact would change her name by becoming Madame Montpelier in a later future, recasts her old self anew by telling "her grandchildren the strange tale of panic in an Australian schoolroom"18 (Lindsay 2009: 137); and seamlessly triggers a pivotal flashback in chapter 15 by pondering on the relationship between Sara Waybourne and the vanished Miranda.

These pasts, all these "fragments of eternity" memory synthesizes consistently make up for a new realization of the present. Each time around, the "new" present decentres the identity of the character by bringing up future manifestations or past rewritings of the said identities. ${ }^{19}$ This dynamic punctuates the idea of discontinuity and fragmentation and calls for a third synthesis of time in order to constitute its proper structure. The synthesis of trauma, as has already been stated, finds its expression in the mystery lurking behind the vanishing episode. Notice that it is not determined or caused, but rather represented by the enigma lying at the center of the "spreading pattern" (Lindsay 2009: 111). The pattern coalesces in the picnic, but it belongs to the structure of the text from the beginning:

At Appleyard College, out of a clear sky, from the moment the first rays of light had fired the dahlias on the morning of Saint Valentine's Day, and the boarders, waking early, had begun the innocent interchange of cards and favours, the pattern had begun to form. Until now, on the evening of Friday the thirteenth of March, it was still spreading; still fanning out in depth and intensity, still incomplete. On the lower levels of Mount Macedon it continued to spread, though in gayer colours, to the upper slopes, where the inhabitants of Lake View, unaware of their allotted places in the general scheme of joy and sorrow, light and shade, went about their personal affairs as usual, unconsciously weaving and interweaving the individual threads of their private lives into the complex tapestry of the whole (Lindsay 2009: 111).

The unfolding of different selves within the various subjectivities the novel zeroes in on emerges as these "individuals" unwittingly "become involved in the spreading pattern," as their lives are "disrupted, sometimes violently" (Lindsay 
2009: 111). The structure articulates the torn condition of said subjectivities and renders it apparent. It constitutes the narrative correlative of the third synthesis of time. Picnic revolves around the trauma of a cultural identity, to wit, the Victorian. Through a fiction of neo-Victorian drive - as will be soon evidenced - the "pattern" unravels the said identity as unhinged, already incapable of securing an affixed, orderly, dependent, protective and predictably unified cultural universe, even as it makes a virtue of pretending to do so by relapsing into chronicle time and again. Fractured identities persistently emerge despite the stifling atmosphere of Appleyard College, a "misfit in time and place" (Lindsay 2009: 7), the enshrining of silence - which is "golden" (Lindsay 2009: 9) for a Victorian culture of oppression - within its gates and the deification of the ticking clock, which resembles "a heart beating in a body already dead" (Lindsay 2009: 172), already fractured and torn. Linear time becomes an impossibility, and so does the unified subject. This impossibility finds its appropriate token, the "symbol adequate to the totality of time" (Deleuze, 2013: 112) in the enigma that coheres into the "spreading pattern" of the Rock (Lindsay 2009: 111). ${ }^{20}$

A pivotal episode in Chapter 12 might both help clarify the idea and disclose its neo-Victorian dimension. Mlle. De Poitiers brings Irma Leopold back to Appleyard College in order to meet her fellow students for the first time after being rescued from the Rock. The schoolgirls are assembled in the gymnasium, dancing to the inexorable beat of a military march (Lindsay 2009: 135). As Irma enters the room, the class turns silent. Evocative images of the picnic then emerge, yet again, with Miranda ${ }^{21}$ placed at the centre. The evocation then turns dark and harrowing, whilst the schoolgirls go into a fit of hysteria. Chaos ensues. Led by Edith, the girls press Irma for an explanation,

"Come on, Irma - tell us. We've waited enough." There was a nudging and muttering. "Edith's right. Tell us, Irma ... Tell us."

"What can I tell you? Have you all gone crazy?"

"The Hanging Rock," Edith said, pushing to the front. "We want you to tell us what happened up there to Miranda and Marion Quade." The more silent of the New Zealand sisters, rarely articulate, added loudly, "Nobody in this rat-hole ever tells us anything!" Other voices joined in: "Miranda! Marion Quade! Where are they?"

"I can't tell you. I don't know" (Lindsay 2009: 137-138).

A great deal of critical comment on Picnic at Hanging Rock relies on the vanishing episode to unravel the potential significance of the novel. However, neo-Victorian readings of the text should privilege the episode of the gymnasium as the actual core of the text. As Anne Heilman and Mark Llewellyn point out, "loss, mourning, and regeneration," trauma and healing, as it were, "are prototypical preoccupations of the neo-Victorian novel" (2010: 34). These narratives usually convey the "re(dis)covery of a personal and/or collective history" marked by trauma and "restitution" (2010: 34). ${ }^{22}$ By and large, the underlying desire of the girls is restitution. The trauma is vividly relived in the episode, but far from being relieved, it brings about a turmoil of anger and frustration. 
Paradoxically enough though, the schoolgirls are looking for healing in the wrong direction. Irma's conspicuous lack of memory derives from the conceptual dissolving of a purportedly unified Victorian identity (or the "rat-hole," as one of the "New Zealand" girls eloquently puts it). Yet only outside the unifying delusion of Victorian identity can the subject not so much restore as to come to terms with trauma, for it is trauma alone which informs the fragmented and disjointed structure of the subject. The girls look for closure and the possibility of meaning in a way that assumes an anteriority to trauma, an original self that can only be restituted after having undergone the anguish of wounds. This alone reveals the nostalgic pull the novel releases - even in the form of a fit of anger, rage and frustration - for "nostalgia," Rosa Karl argues, "propels our identity work" (2010: 47 ), and as such informs, at least in part, the desire underlying neo-Victorian fiction. Indeed, nostalgia "attempts to possess a revised version of history and / or literature via a narration that transforms it into personal experience" (Karl 2010: 47). This prompts a (re)negotiation of the present or postmodern self, possibly in search for restitution via Victorian subjectivity, a "performance in which the demarcations of difference between" the Victorian "and us may effectively be dissolved" (Thomas 2000: 307); and proves the "productive" quality of "nostalgia" as it "[gives] voice to the desire for cultural memory" neo-Victorian fiction "bear[s] witness" to (Mitchell 2010: 5). Irma's total absence of memory, however, enables the possibility of "reconstruction" through "fragmented, fabricated, or repressed memories" (Heilmann and Llewellyn 2010: 34). All these encapsulate, one way or another, the logic of neo-Victorian fiction, the "story of difference" (Heilmann and Llewellyn 2010: 15) underlying the re-writing of Victoriana. With a metafictional slant, the episode mirrors "the origins of the neo-Victorian genre and the narratological traditions it seeks to reshape" (Heilmann and Llewellyn 2010: 34). Reading the certainties of the Victorian self in Picnic, in short, reveals the trauma that structures subjectivity and upends, in passing, the notion of Victorian identity as a grand narrative.

Present subjectivities then become haunted by the enigma of trauma, in keeping too with neo-Victorian fiction, which is often "preoccupied with images of ghosts and metaphors of haunting, especially positioning the fictional text as a medium of the past" (Mitchell, 2010: 35). The "ghost," Mitchell proceeds, "signals $[\ldots]$ the uncanny repetition of the past in the present" (2010: 35), for "there is no distinction between past and present, inside and outside in a haunted subject or a haunted text" (Arias and Pulham 2009: xvii). As a result, "haunted" neo-Victorian fictions bring home an oblique notion of "indeterminacy and incompletion" (Mitchell 2010: 35) which informs its internal logic as well as its metafictional drive. As is the case in Picnic, the "pattern" and the enigma ${ }^{23}$ structure the present by recurring unremittently, "not merely" as "spirit[s] of the past, but" largely as "agent[s] of the future" (Arias and Pulham 2009: xiv). In Deleuzean terms, this would signal the "eternal return" of "difference" (2013: 153), the ongoing and ceaseless (re)affirmation of "indeterminacy" and "incompletion" inscribed in the haunting. Yet this works both inwards and outwards, as the "pattern" "darken[s] and spread[s]" beyond its internal logic, not "unseen" or "unrecorded" (Lindsay 2009: 122) any longer, but fully disclosed in the self-awareness of the text. 


\section{Conclusion}

A note at the beginning of the novel, after the "List of Characters," encourages the reader to ponder on the nature of the text.

Whether Picnic at Hanging Rock is fact or fiction, my readers must decide for themselves. As the fateful picnic took place in the year nineteen hundred, and all the characters who appear in this book are long since dead, it hardly seems important (Lindsay 2009: 6).

The note does not encourage readers to verify the truth of events on the logic of the text - a postmodern impossibility in itself - let alone to resort to paratextual evidence to the same end. ${ }^{24}$ Rather, the note points out the self-contradictory nature of Picnic as well as the underlying neo-Victorian drive the novel performs. "Victoriana sometimes dispenses of historical narrative altogether," Cora Kaplan upholds (2007: 87), and sometimes it plays upon the historical mode to disclose that "its precise temporality, like its 'truth,' is uncertain" (Kaplan 2007: 87). Reading Picnic as a chronicle of "facts," subject to linear time and causal interconnections, assumes a concept of history that plays upon received notions of Victorianism. Its alleged lack of "importance" stems precisely from the idea of time it favours. Reading the novel as a pattern of "fiction" conversely reveals a fractured subject that constantly affirms the very element which articulates its fracture (and renders it apparent), the ongoing return of difference in the form of a haunting enigma of trauma. This kind of reading displaces the core of Victorian identity, constantly deferring the promise of meaning in the unavoidable process of constituting the "I" through memory and trauma. And it is indeed "important," insofar as it affects the subjectivity invested in the process of decision, i.e., the reader. In fact, the very notion of "having to" make $a$ decision is specious in itself. The text does not expect an answer, even as it does not provide readers with a solution to the mystery. It is in the very process of decision, as an eternally-deferred closure or a multifarious, fragmented present, that the self-contradictory logic of Picnic renders its neo-Victorian slant fully apparent, since it obliquely defines the project as an ongoing and unresolved drive to grasp the memory of difference Victorianism left untold.

\section{Notes}

$1 \quad$ Nadia Boehm-Scnhitker and Susanne Gruss refer to the body of neo-Victorian texts as a "project." Back in 2010 they already understood that "the processes of canonisation not only [began] to fossilise the body of works and media to be addressed under the heading of neo-Victorianism but also some critical approaches, theories and predominant concerns" (2010: 4). The term "project" has proven - and still is - very useful to signal the incompleteness of the neo-Victorian canon, as well as the ample field of discussion, yet unexplored, neo-Victorian criticism still offers.

$2 \quad$ The novel has spawned two major eponymous adaptations, a celebrated film (Peter Weir, 1975) on the one hand and a TV mini-series (Larysa Kondracki, 2018) on the 


\section{Eduardo Valls Oyarzun}

other, as well as several stage adaptations, including a musical in 2014. The interest in the phenomenon keeps moving routinely due to "the paratexts that surround text and film, such as urban mythology, interviews with participants [...] and the 1987 publication of The Secret of Hanging Rock, the final chapter edited out from the original book" (Bladen 2012: 160).

3 This is not a problem of time-frame. Even though neo-Victorian fiction "achieves momentum," circa 1980, thirteen years after the novel was published, that is, "at around the time when personal memory of the Victorians was slipping away" (Mitchell 2010: 12), neo-Victorian studies have not neglected the analysis of texts published earlier than the 1980s. Discussions on the foundational texts of neoVictorianism usually comprise John Fowles' The French Lieutenant's Woman (1969) and / or Jean Rhys' Wide Sargasso Sea (1966) (Karl 2010: 44; Mitchell 2010: 18; Heilmann and Llewellyn 2010: 8, 67; Ho 2010: 167) and Cora Kaplan locates the beginning of the cultural reprise of Victoriana in the late 1960s (2008: 88). It is not a national issue either, for Oscar and Lucinda (1987) and Jack Maggs (1997) by Australian author Peter Carey typically feature in most examinations of the neoVictorian canon, whereas Dutch-born, Australian-raised Michel Faber (The Crimson Petal and the White, 2002) ranks among the most-studied neo-Victorian authors of the century (possibly only second to Sarah Waters).

$4 \quad$ Wild's remark refers to Peter Weir's eponymous film adaptation (1975) of Lindsay's novel, but I argue it befits the novel too. Victoria Bladen's critical assessments, although implicitly, intimates the novel, the film and "the paratexts that surround both" as a "phenomenon of the cultural Australian landscape" (2010: 160).

$5 \quad$ Matthews argue these - bar "decay" - rank too among the "popular" - i.e., conventional - "stereotypes of Victorianness" that "have endured" to date (2010: 274).

$6 \quad$ The novel spans a month and a half, from Valentine's Day (February, 14) 1900 to March, 27 on the same year. The narrator provides seventeen different dates all the way through to the end of the text (Lindsay 2009: 5, 7, 43, 47, 59, 63, 90, 95, 111, $128,130,137,147,162,178,184,185)$.

7 The alternative time frame the novel sets up is the "pattern." See sections 3-5 for a comment on the notion of "pattern" as narrative structure in the novel.

8 Not exclusively, though, for the idea is far from being unproblematic. As Heilmann and Llewellyn acknowledge, there is "such a thing as a Victorian experience that cannot always be recast into a story of neo-Victorian difference," but rather "marks a return to" the "potential certainties, satisfactions and comforts" beyond "narrative innovation, fragmentation and the invention of new forms" encouraged by "postmodern experimentation" (2010: 15-16).

$9 \quad$ The idea resonates, albeit from a totally different angle, with Marie-Luise Kohlke's discussion on the contrast between "historical fiction" and neo-Victorian narratives. According to Kohlke, "unlike, say, ancient civilisations, the Victorian consists not so much of relics and ruins as of pervasive embodied / incarnate material" that comprises "an integral part of the lived / living fabric of the present." They make up for "traces structuring today's cultural institutions, political and socio-economic frameworks, and the landscapes, cityscapes and global spaces we inhabit” (Kohlke 2010: 29).

10 Interpretations in keeping with Kirkby's reading abound, hence their normativity. Marek Haltof (1996) and Jytte Holmqvist (2013: 25-35) agree with Kirby, albeit with nuances. Kathleen Steele, on the other hand, upholds that Victorian characters "display an obsession with time" in order to "keep the chaos," not the absence, "of natural time from their door" (2010: 44).

11 The complexity of Deleuze's model exceeds the limits of the summary conveyed in the following paragraphs. Nathan Widder (2006), Hans Le Bolle (2010) and James Williams (2011) provide ample discussions of Deleuze's ideas on time, particularly in connection with his philosophy of difference. 
A synthesis, or a contraction does not refer to "an instantaneous action which combines with another to form an element of repetition, but rather [to] the fusion of that repetition" in the imagination. In that sense, "repetition" and, consequently, time are "imaginary" (Deleuze 2013: 95, 97).

Deleuze associates these to the philosophy of Hume, Bergson and Nietzsche respectively (2013: 92, 101, 112).

In Deleuze's model, the "present" is not "a dimension in time." On the contrary, the "synthesis constitutes time as a [...] present," for "the present alone exists" (2013: 97). Deleuze refers to trauma, not a particular instance of trauma, but trauma. Freudian psychoanalysis finds a characteristic image to project onto trauma in the structure of the Oedipus. This is problematic. The Oedipus, as suggested by Widder's example, aims to salvage identity as an "origin" or an "essence," an objectifiable self - which psychoanalysis enables to unravel - which becomes torn after the trauma. Deleuze claims otherwise. The Oedipus might work as a way to characterize trauma, but it is merely its representation.

"Difference," Deleuze upholds, "inhabits repetition," precisely because it "lives between two repetitions" (2013: 97).

The novel makes a point of the landscape being pure, untouched, for "there are no tracks on this part of the Rock" and "if there ever have been tracks, they are long since obliterated" (Lindsay 2009: 30). This suggests that the articulation of the landscape in time precisely depends on a self that synthesizes it in time.

This refers to Irma's return to Appleyard College after being found on the Rock. See below for a discussion of this particular episode in section 4 .

In the "List of characters" that opens the book, Lindsay provides a cast of names tagged with their role in the novel. The last line in the list refers to "many others who do not appear in this book" (Lindsay 2009: 6). The quip is particularly suggestive in that it includes all the past selves that are not present - i.e., in praesentia, occurring in a particular place in the novel - but belong to each character that is made present - i.e., existing now. The multitude of selves pertaining multitude temporalities are also hinted at in the "millions and millions of cells" and "millions and millions of seconds" Marion points out to Edith during the ascent to the Rock (Lindsay 2009: $30)$.

In terms of representation, the vanishing episode - the mystery - enables the characters to negotiate the particular subjectivities Picnic unfolds each time it zeroes in on a specific character. They all emerge by virtue of the mystery, even though they are not caused - neither directly nor indirectly - by it.

Miranda represents the best synecdoche of the enigma. Her name, "to be admired" refers a sign of the mystery. Sara's infatuation with the character underscores the spreading of the pattern over her character.

Although Heilman and Llewellyn focus on the restitution of a "family inheritance" (2010: 34), their argument ponders on the cultural value the inheritance brings along.

The recurring "pattern" informs the haunting in Picnic. Yet the text also posits a spectre or a ghost in the character of Miranda, whose pervasive virtual apparitions after the vanishing episode renders trauma visible.

This is a common popular (mis)interpretation of the note. Picnic at Hanging Rock has spawned countless popular comments, most notably on the vanishing episode. "In most cases," at best, these "have spiralled into wild theories" (Steele 2010: 43). John Taylor (1987) provides an interesting account of the mainstream debate on the novel. Some academics have too resorted to paratextual evidence to construe the text, but with good motive. Lindsay's editors advised the author to edit Chapter 18 out of the novel (Taylor 1987). The chapter purportedly explained the mystery behind the vanishing episode (readers of Chapter 18 will undoubtedly understand 


\section{Eduardo Valls Oyarzun}

why the explanation is "purported"). The chapter was never restored (no edition of the novel includes it), but it was finally published three years after Lindsay's death, in 1987. Authors like Victoria Bladen (2012: 160) or Adam Hulbert (2009: 46-49) include the chapter in their assessment of the novel.

\section{References}

Arias, Rosario and Pulham, Patricia (2009). Introduction. In: Arias, Rosario and Pulham, Patricia (eds.) Haunting and Spectrality in Neo-Victorian Fiction: Possessing the Past. Basingstoke: Palgrave Macmillan, i-xxvi.

Armellino, Pablo (2009) Ob-scene Spaces in Australian Narrative: An Account of the Socio-topographic Construction of Space in Australian Literature. Stuttgart: Verlag.

Bladen, Victoria (2012) The rock and the void: Pastoral and loss in Joan Lindsay's Picnic at Hanging Rock and Peter Weir's film adaptation. Colloquy 23, 159-184.

Boehm-Schnitker, Nadine and Gruss, Susanne (2010) Introduction. In: Boehm-Schnitker, Nadine and Gruss, Susanne (eds.) Neo-Victorian Literature and Culture: Immersions and Revisitations. London and New York: Routledge, 1-17.

Chalupský, Petr (2020) Non-normative Victorians: Ian Maguire's The North Water as a neo-Victorian novel. Brno Studies in English 46(2), 103-118. https://doi.org/10.5817/ BSE2020-2-6.

Crick, Malcolm (1985) Corsets, culture and contingency: Reflections on Joan Lindsay's Picnic at Hanging Rock. Mankind 15 (3), 231-242.

De Bolle, Leen (2010) Deleuze's passive synthesis of time and the dissolved self. In: De Bolle, Leen (ed.) Deleuze and Psychoanalysis: Philosophical Essays on Deleuze's Debate with Psychoanalysis. Leuven: Leuven University Press, 131-156.

Deleuze, Gilles (2013 [1968]) Difference and Repetition. Paul Patton, trans. London and New York: Bloomsbury.

Haltof, Marek (1996) The spirit of Australia in Picnic at Hanging Rock: A case study in film adaptation. Canadian Review of Comparative Literature 23 (3), 809-822.

Heilmann, Ann and Llewellyn, Mark (2010) Neo-Victorianism. The Victorians in the Twenty-First Century, 1999-2009. Basingstoke: Palgrave Macmillan.

Ho, Elizabeth (2010) The neo-Victorian at sea: Towards a global memory of the Victorian. In: Boehm-Schnitker, Nadine and Gruss, Susanne (eds.) Neo-Victorian Literature and Culture: Immersions and Revisitations. London and New York: Routledge, 165-178.

Holmqvist, Jytte (2013) Contrasting cultural landscapes and spaces in Peter Weir's film Picnic at Hanging Rock (1975), based on Joan Lindsay's 1967 novel with the same title. Coolabah 11, 25-35. https://doi.org/10.1344/co20131125-35.

Hulbert, Adam (2016) The precarity of the inarticulate: Two kinds of silence in Joan Lindsay's Picnic at Hanging Rock. Philament 22, 27-55.

Jameson, Frederic (2003) The Political Unconscious: Narrative as a Socially Symbolic Act. London and New York: Bloomsbury.

Kaplan, Cora (2007) Victoriana: Histories, Fictions, Criticism. New York: Columbia University Press.

Karl, Rosa (2010) Participatory desires: On metalepsis, immersion and the re-plotting of the Victorian. In: Boehm-Schnitker, Nadine and Gruss, Susanne (eds.) Neo-Victorian Literature and Culture: Immersions and Revisitations. London and New York: Routledge, 38-50.

Kirkby, Joan (1978) Old orders, new lands: The earth spirit in Picnic at Hanging Rock. Australian Literary Studies 8 (3), 248-270.

Kohlke, Marie-Luise (2010) Mining the neo-Victorian vein: Prospecting for gold, buried treasure and uncertain metal. In: Boehm-Schnitker, Nadine and Gruss, Susanne (eds.) Neo-Victorian Literature and Culture: Immersions and Revisitations. London and New York: Routledge, 21-37. 
Lindsay, Joan (2009 [1967]) Picnic at Hanging Rock. London and New York: Vintage.

Matthews, Samantha (2010) Remembering the Victorians. In: O'Gorman, Francis (ed.) The Cambridge Companion to Victorian Culture. Cambridge: CUP, 275-282.

Mayr, Suzette (2017) "Misfit" college: The sentient house as thing in Joan Lindsay's Picnic at Hanging Rock. Antipodes 31 (2), 393-406. https://doi.org/10.13110/antipodes.31.2.0393.

McCarthy, Claire (2018) Adaptations down under: Reading national identity through the lens of adaptation studies. In: Cutchins, Dennis, Krebs, Katja and Voigts, Eckart (eds.) The Routledge Companion to Adaptation. London and New York: Routledge, 217-231.

McFarlane, Brian (1983) Words and Images. Australian Novels into Film. Melbourne: Heinemann. Mitchell, Kate (2010) History and Cultural Memory in Neo-Victorian Fiction. Basingstoke: Palgrave Macmillan.

Rousseau, Yves (1987) Commentary on Chapter Eighteen. In: Taylor, John (ed.) The Secret of Hanging Rock. Sydney: ETT Imprint. E-book.

Steele, Kathleen (2010) Fear and loathing in the Australian bush: Gothic landscapes in Bush Studies and Picnic at Hanging Rock. Colloquy 20, 33-56.

Taylor, John (1987) The invisible foundation stone. In: Taylor, John (ed.) The Secret of Hanging Rock. Sydney: ETT Imprint. E-book.

Thomas, Ronald R (2000) Specters of the novel: Dracula and the cinematic afterlife of the Victorian novel. In: Kucich, John and Sadoff, Dianne (eds.) Victorian Afterlife: Postmodern Culture Rewrites the Nineteenth Century. Minneapolis: University of Minnesotta Press, 288-310.

Tilley, Elspeth (2009) The uses of fear: Spatial politics in the Australian white-vanishing trope. Antipodes 23 (1), 33-41.

Tilley, Elspeth (2012) White Vanishing: Rethinking Australia's Lost-in-the-bush Myth. Amsterdam and New York: Rodopi.

Valls Oyarzun, Eduardo (2017) Dueños del Tiempo y del Espanto: Genealogía Nietzscheana de la Responsabilidad en la Narrativa Victoriana. Madrid: Escolar y Mayo.

Widder, Nathan (2010) Time is out of joint - and so are we: Deleuzean immanence and the fractured self. Philosophy Today 50 (4), 405-417.

Wild, Harriet (2014) Darling Miranda: Courtly love in Picnic at Hanging Rock. Studies in Australasian Cinema 8 (2), 123-132. https://doi.org/10.1080/17503175.2014.960681.

Williams, James (2011) Gilles Deleuze's Philosophy of Time. Edinburgh: Edinburgh University Press.

Eduardo Valls Oyarzun is Associate Professor at the English Department (Linguistics and Literature), Complutense University of Madrid, where he finished his $\mathrm{PhD}$ after completing an MA on English Literature at Leiden University. He teaches courses on Victorian Literature, Literary Studies and Visual Cultures. He specializes in Nineteenth Century fiction and has published extensively on Oscar Wilde, George Bernard Shaw, Joseph Conrad and Lewis Carroll. His main research interests comprise the fields of Victorian Studies, neo-Victorian Fiction and the History of Ideas.

Address: Prof. Dr. Eduardo Valls Oyarzun, BA, MA (Hons), PhD. Department of English Studies: Linguistics and Literature, Office 322. School of Philology, Complutense University of Madrid, Plaza Menéndez Pelayo s/n, 28040, Madrid, Spain. [email: evallsoy@ucm.es] 
